\title{
The psychosocial impact of acne, vitiligo, and psoriasis: a review
}

This article was published in the following Dove Press journal:

Clinical, Cosmetic and Investigational Dermatology

20 October 2016

Number of times this article has been viewed

\author{
Catherine M Nguyen' \\ Kourosh Beroukhim² \\ Melissa J Danesh ${ }^{3}$ \\ Aline Babikian ${ }^{4}$ \\ John $\mathrm{Koo}^{3}$ \\ Argentina Leon ${ }^{3}$ \\ 'University of California, Irvine \\ School of Medicine, Irvine, ${ }^{2}$ David \\ Geffen School of Medicine at \\ UCLA, Los Angeles, ${ }^{3}$ Department of \\ Dermatology, University of California \\ San Francisco School of Medicine, \\ San Francisco, ${ }^{4}$ Touro University \\ College of Osteopathic Medicine, \\ Vallejo, CA, USA
}

Introduction: Chronic skin conditions have been well reported to affect a patient's quality of life on multiple dimensions, including the psychosocial domain. Psychosocial is defined as the interrelation of social factors with an individual's thoughts and behavior. The assessment of the psychosocial impact of skin disease on a patient can help direct the dermatologists' treatment goals. To evaluate the psychosocial impact of skin disease, we conducted a review of the literature on three skin conditions with onsets at various stages of life: acne, vitiligo, and psoriasis.

Methods: A PubMed search was conducted in March 2015 using the terms "psychosocial” AND "acne", "psychosocial" AND "vitiligo", and "psychosocial" AND "psoriasis". The results were limited to articles published in English in the past 5 years studying patients of all ages. Results and their references were evaluated for relevance according to their discussion of psychosocial qualities in their patients and the validity of psychosocial assessments. The search for acne yielded 51 results, and eleven were found to be relevant; vitiligo yielded 30 results with ten found to be relevant; and psoriasis yielded 70 results with seven found to be relevant.

Results: According to the articles evaluated, 19.2\% of adolescent patients with acne were affected in their personal and social lives. Social phobia was present in $45 \%$ of patients with acne compared to $18 \%$ of control subjects. Race and sex played a role in self-consciousness and social perceptions of the disease. Vitiligo negatively affected marriage potential and caused relationship problems in $>50 \%$ of patients. Psoriasis negatively affected multiple domains of life, including work, relationships, and social activities. Anxiety and depression affected not only psoriasis patients but also their cohabitants; up to $88 \%$ of cohabitants had an impaired quality of life.

Conclusion: Though all three skin conditions resulted in an increase in anxiety and depression among their patient populations, the psychosocial focus varied slightly for each disease. Overall, acne, vitiligo, and psoriasis can have negative psychosocial impact in different stages of life development.

Keywords: psychosocial, acne, psoriasis, vitiligo

\section{Introduction}

Chronic skin conditions have been well reported to affect a patient's quality of life (QOL) on multiple dimensions, including the psychosocial domain. Psychosocial is defined as the interrelation of social factors with an individual's thoughts and behavior. ${ }^{1}$ Because many skin conditions are commonly associated with social stigmatization, patients can suffer from lowered self-esteem, anxiety, or depression. The assessment of the psychosocial impact of skin disease on a patient can help direct the dermatologists' treatment goals.

\footnotetext{
Correspondence: Catherine M Nguyen University of California, Irvine School of Medicine, I00I Health Sciences Road, Irvine, CA 92617, USA Email cnguyen2082@gmail.com
}

(c) (1) (5) 2016 Nguyen et al. This work is published and licensed by Dove Medical Press Limited. The full terms of this license are available at https://www.dovepress. com/terms. cc) ${ }_{\mathrm{BY}} \mathrm{NC}$ php and incorporate the Creative Commons Attribution - Non Commercial (unported, v3.0) License (http://creativecommons.org/licenses/by-nd/3.0/). By accessing the work you hereby accept the Terms. Non-commercial uses of the work are permitted without any further permission from Dove Medical Press Limited, provided the work is properly attributed. For

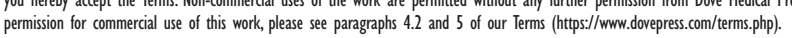


To evaluate the psychosocial impact of skin disease, we conducted a review of the literature on three skin conditions with onsets at various stages of life: acne, vitiligo, and psoriasis. Acne vulgaris is found in $85 \%$ of adolescents, and approximately two-thirds of adults 18 years and older ${ }^{2}$ with the most represented age group between 15 and 17 years. $^{3-5}$ Vitiligo affects $\sim 1 \%$ of the population, usually beginning either in the ages of 10-30 or later in life, with an average age of 56.5. ${ }^{6,7}$ Lastly, psoriasis has a bimodal age distribution of onset, which peaks in the $20 \mathrm{~s}$ and $60 \mathrm{~s} .{ }^{8}$ Because each age group differs in terms of priorities and social activities, the psychosocial effects of these skin conditions can vary with age. By recognizing the psychosocial influence of these skin conditions, the dermatology provider can better understand the impact on the patient as a whole, including the physical, mental, and emotional domains, in order to guide treatment, and provide resources for group support and appropriate referrals.

\section{Methods}

A PubMed search was conducted in March 2015 using the terms "psychosocial" AND "acne", "psychosocial" AND "vitiligo", and "psychosocial" AND "psoriasis". The results were limited to articles published in English in the past 5 years. The search was inclusive of papers addressing patient populations of all ages. Results and their references were evaluated for relevance according to their discussion of psychosocial qualities in their patients. Relevance was determined by reviewing the article in its entirety. Papers discussing the psychosocial impact of disease, including issues in relation to marriage, school, work, friendships, or team activities, were deemed to be relevant over paper discussing QOL issues that affected only the patient. Additionally, papers discussing anxiety and depression were deemed relevant due to the impact of these psychiatric conditions on the patient's social activities. The search for acne yielded 51 results, and eleven were found to be relevant; vitiligo yielded 30 results with ten found to be relevant; and psoriasis yielded 70 results with seven found to be relevant.

\section{Results}

\section{Acne}

Shahzad et al distributed the Cardiff Acne Disability Index to 950 college students and found that acne had a greater psychosocial impact on females when compared to males. ${ }^{9}$ Social phobia was diagnosed in $45.7 \%$ of high school patients with acne when compared to $18.4 \%$ of control subjects in a study by Bez et al. ${ }^{10}$ Thus, social phobia was concluded to be a common psychiatric comorbidity that greatly disabled the patients' lives. Social bullying was perceived to be experienced by a significantly higher number of teenagers with acne when surveyed. ${ }^{11}$ Furthermore, using the Liebowitz Social Anxiety Scale, it was shown that patients with acne had higher avoidance scores than controls and were more negatively affected in their occupational, social, and familial lives. Intrapsychic consequences, such as self-consciousness, were found to be significantly increased in patients with acne after administration of the Acne Symptom and Impact Scale by Alexis et al. ${ }^{12}$ These patients also expressed annoyance, lowered confidence (in the majority of women, $>75 \%$ ), social withdrawal, and bothersomeness. ${ }^{13}$ Additionally, the likelihood of experiencing perceived stigma was three times higher for patients with acne. ${ }^{14}$ Racial differences in social perceptions and self-consciousness of female patients were studied by Callender et al. ${ }^{13}$ More White/Caucasian women felt self-conscious around other people (85\%) when compared to non-White/Caucasian $(68.3 \%, P<0.05)$. However, more non-White/Caucasian females felt that those without acne could not relate to experiencing adult acne $(66.3 \%$ vs $57.9 \%, P<0.05) .{ }^{13}$ Indian women felt that physical attractiveness increased the ability to secure jobs and life partners but ultimately expressed that the true nature and qualities of a person were more important long term for these domains. ${ }^{15}$

General QOL also assessed in patients with acne, particularly pertaining to the social aspects. When the Dermatology Life Quality Index (DLQI) responses were analyzed individually by Tasoula et al, it was found that $21 \%$ of the adolescents were affected in their school work and personal activities due to acne. ${ }^{16}$ Approximately $19 \%$ were affected in their hobbies, and 19.2\% were affected in their personal lives, particularly in relationship building. In terms of hobbies, $14 \%$ of patients avoided swimming and other sports due to embarrassments. In a study of 160 Saudi-Arabian patients, $13.3 \%$ stated that acne affected school performance, while $21.1 \%$ spousal relationship, $30 \%$ marriage willingness, and $17.2 \%$ friendship relations. ${ }^{17}$

Lastly, depression and anxiety were found to be increased in patients with acne. Marron et al also administered the Hospital Anxiety and Depression Scale to patients before and after isotretinoin treatment. ${ }^{18}$ The mean anxiety score was 8.9 out of 21 before treatment, which is higher than that of the general population denoting higher levels of anxiety. Approximately $26 \%$ of patients before treatment qualified as clinical cases (a high score $>11$ ). After treatment with isotretinoin, only $3.5 \%$ of patients met this criterion, supporting the role that acne plays in the development of anxiety. 
Depression was clinically significant in 12 of 346 patients (3.5\%). Kubota et al distributed the Mental Health Inventory (MHI) or the Short Form-36 to Japanese adolescents. ${ }^{19}$ Students with acne were significantly more depressed than those without skin problems, and girls were more significantly affected than boys. The time span in which the patient was affected by acne also affected the MHI score, as patients with acne for $>2$ years had significantly lower MHI scores than those with acne for $<6$ months. Concerning adult females, it was found by Callender et al through administration of the Patient Health Questionnaire that $71 \%-73 \%$ of patients experienced some degree of anxiety or depression. ${ }^{13}$ There was no significant difference in the rate of depression or anxiety with regard to race (White/Caucasian vs non-White/ Caucasian). ${ }^{13}$ Overall, anxiety and depression in patients with acne are multifactorial, with sex and duration, but not race, affecting severity.

\section{Vitiligo}

Patients with vitiligo felt a perpetual burden due to the unpredictability of the disease and the measures needed to hide the disorder, either by makeup or clothing. ${ }^{20}$ The significant psychosocial impact is evident in the case of patients who reported that they thought about their condition all throughout the day, and were dissatisfied looking into a mirror, even with the lesions covered. ${ }^{21}$ This dissatisfaction with their appearance led to a weak self-perception, commonly resulting in worry, depression, and low self-esteem. ${ }^{21}$ While vitiligo does not pose a formidable challenge physically, it does have profound detrimental impact on a patient's well-being and QOL unrelated to the extent of the disorder. ${ }^{22-24}$

In many patients, vitiligo has led to a sense of disfigurement and disempowerment. This negative mentality has behavioral consequences for patients with vitiligo in terms of social and physical involvement. According to a study by Talsania et al, $>75 \%$ of patients experienced face and hand vitiligo, which are highly visible regions. A majority of patients believed this visible difference in color on their face and hands to be the most disfiguring and to have a profound effect on their self-esteem. Many patients avoided physical activities with significant sun exposure, such as swimming, in order to prevent sunburn to these areas. ${ }^{6}$ There are also cases of students with vitiligo who were compelled to withdraw from organized school events or from attending traditional schools, in exchange for correspondence courses, due to frequent doctor visits and the taunting they experienced at school. ${ }^{21}$

In many conservative male-dominated societies, vitiligo is a highly stigmatized disorder. For example, in Saudi Arabia, patients with vitiligo are often perceived as contagious (33.1\%). ${ }^{25}$ In British South Asian societies, patients not only faced rejection from family and society but in many cases experienced detachment from their ethnicity as well. Many patients have developed a "spoiled identity", or ruined and weakened sense of identity, to internalize the isolation and stigmatization they have endured. ${ }^{20}$

Vitiligo was also noted to be a barrier to marriage, ${ }^{20}$ which is a fundamental milestone of most traditional societies. Studies have shown that over half of those with vitiligo found it challenging to meet strangers or begin emotional or sexual relationships. Based on a questionnaire, over half (56.1\%) of 898 male and female subjects residing in Saudi Arabia stated that they would not consider marrying an individual with vitiligo. ${ }^{20}$ Of those who did marry, the quality and stability of relationships were noted to be lower compared to those who did not have vitiligo. ${ }^{26}$ In a study of Indian patients with vitiligo, married females had a higher DLQI, and thus lower QOL, than married males, which was attributed to discrimination and relationships with the in-law relatives. ${ }^{27}$ There are cases of patients who did not disclose their disorder to their spouses before marriage for fear of rejection. Even after marriage, in-law conflicts were not uncommon, with one documented case of a patient who was encouraged to divorce if she was not cured. ${ }^{21}$

Depression is a serious repercussion of this disease. The degree of the relationship between vitiligo and depression may be culturally specific. In Singapore, depression was noted to be present in $16.2 \%$ of patients with vitiligo based on the Epidemiologic Studies Depression Scale, a 20 -item test with scores ranging from 0 (none or rare) to 3 (most of the time) within 5-7 days, and a likely diagnosis of depression for total scores $\geq 16$. $^{22}$ Depression was also prevalent among patients with vitiligo in Italy, 31\%, based on responses of "often" or "all the time" on the Skindex-29, which is a five-point dermatology-specific tool with answers that range from "never" to "all the time" to determine the impact of a disorder on QOL. ${ }^{24}$ The percentage of vitiligo associated with depression, as well as anxiety, was even higher $(>50 \%)$ based on the illness perception questionnaire, in Arab society. Lastly, depression was found in 59\% of Indian patients with vitiligo. ${ }^{27}$ This variance may be due to differences in base skin color or cultural ideations of vitiligo. ${ }^{25}$ In the Arabic and Italian studies, females were noted to be affected more frequently than males. ${ }^{24,25}$ Suicidal ideation is a documented consequence of the emotional burden inflicted upon patients, particularly among those who coped poorly with the disorder. ${ }^{21}$ 


\section{Psoriasis}

Studies concerning the psychosocial aspects of psoriasis were focused on both the patient's family and the public's perception of psoriasis. Sampogna et al administered both the Skindex-29, which focuses on physical symptoms, and the Skindex-17, which focuses on the psychosocial aspects of disease, to patients with psoriasis. ${ }^{24}$ It was found that patients had both physical and psychosocial impairment. In terms of familial life, Martinez-Garcia et al found that $87.8 \%$ of cohabitants of patients with psoriasis also had impaired QOL. ${ }^{28}$ The DLQI for families was significantly associated with the psoriasis patient's DLQI. In fact, anxiety and depression levels measured using the Hospital Anxiety and Depression Scale did not differ between patients and cohabitants but were higher than that of control groups. This suggests that the impact of psoriasis extends beyond the patients to include their cohabitants, impairing both the internal and external psychosocial dimensions.

In a web-based survey by Anstey et al, it was found that important social issues highlighted were a lack of understanding of psoriasis by the public, avoidance, or limitation of social activities. ${ }^{29}$ The abilities of patients to interact socially and make new friends were negatively affected, often leading them to cancel social engagements they previously agreed to attend. Bewley et al found that depressive symptoms in patients with psoriasis were associated with health-impairing behavior such as smoking, drinking, and decreased physical activity. ${ }^{30}$ Difficulties with work were particularly more prominent in patients with palmoplantar psoriasis. ${ }^{24}$ In fact, Armstrong et al noted that of 5,604 patients with psoriasis surveyed in the USA, $12 \%$ were unemployed, and $92 \%$ of those unemployed cited psoriasis as the sole cause. ${ }^{31}$ Of patients who continued to work, $49 \%$ missed days of work regularly due to their psoriasis. Patients with severe psoriasis had a 1.8 times greater chance of being unemployed.

Cather specifically studied women of childbearing age with psoriasis and found that there was a lower rate of pregnancy when compared to the control group. ${ }^{32}$ In women $<35$ years of age, the likelihood of pregnancy was $22 \%$ lower than the average, nondiseased population. Women with psoriasis also tended to have fewer children than controls. In a series of 60 interviews with women with psoriasis, all patients reported an adverse impact on their intimate relationships, with $91 \%$ related to sexual desire and $79 \%$ sexual ability. ${ }^{32}$ Thus, both psychological and clinical aspects may be contributing factors to the negative impact on work (Table 1).

\section{Discussion}

Herein, we present a brief review of the psychosocial impact of three dermatological conditions with various ages of onset. The different ages of onset for acne, vitiligo, and psoriasis are reflected in the various psychosocial effects discussed for each disease. The psychosocial effects seem to correlate with the Erickson Stages of Development that address the psychosocial conflict and primary relationships formed in each age group (Table 2). For adolescents, the main internal conflict lies in identity vs confusion, with the development of peer relationships. For early adulthood of 20-25 years, intimacy is the core psychosocial issue with the development of friends and lovers. Lastly, for middle adulthood of 26-64 years, generativity vs stagnation is the conflict, with family and society as the dominant relationships formed. All three skin conditions were reported to result in similar intrapsychic effects among their patient population, such as increase in anxiety and depression. However, the literature revealed a specific psychosocial focus for each disease that varied from one another.

\section{Acne and social interactions}

Acne has been shown to negatively impact self-esteem and identity formation in a majority of the adolescent population suffering from it. Of the literature reviewed, the psychosocial consequences were found to be focused on the patients' social interaction, such as relationships with friends and hobbies. In contrast to vitiligo, long-term, serious relationships were not discussed, most likely due to the prevalence of the disease in a younger age group and the temporary nature of acne. Race and sex also played a role, with females suffering from a more negative psychosocial impact and White/Caucasians being more self-conscious around other people. Non-White/ Caucasian females were more sensitive to how others without adult acne may relate to them.

Since the age of adolescence is often a time of identity formation and vulnerability to peer acceptance and opinions, patients' social interactions are more impaired as symptom severity increases. Social phobia was found to be significantly higher in patients with acne, yet it was not mentioned in the literature for patients with vitiligo or psoriasis. Likewise, family and marriage were common themes in vitiligo and psoriasis, respectively, but they were not found to be relevant in studies on acne. This difference can be explained by a greater focus on oneself during adolescence. Social interaction during the years of adolescence can be said to be self-centered when compared to the priorities of a more mature age group, where family and marriage are of greater concern. The impact of acne on the self-centered psyche of adolescence can be demonstrated 
Table I Summary of papers reviewed and their findings, organized by disease discussed

\begin{tabular}{|c|c|c|c|c|c|}
\hline Author & Title & Year & Size & Survey & Findings \\
\hline \multicolumn{6}{|l|}{ Vitiligo } \\
\hline Sangma et $\mathrm{al}^{27}$ & $\begin{array}{l}\text { Quality of life and psychological } \\
\text { morbidity in patients with } \\
\text { vitiligo: a study in a teaching } \\
\text { hospital from north-East India }\end{array}$ & 2015 & $n=100$ & $\begin{array}{l}\text { DLQI, Hamilton } \\
\text { Depression Rating } \\
\text { Scale }\end{array}$ & $\begin{array}{l}\text { Married females have a lower quality of life } \\
\text { than married males due to discrimination } \\
\text { and in-law relationships } \\
59 \% \text { of patients with vitiligo had depression }\end{array}$ \\
\hline Pahw et $a^{21}$ & $\begin{array}{l}\text { The psychosocial impact of } \\
\text { vitiligo in Indian patients }\end{array}$ & 2013 & $n=50$ & Interview & $\begin{array}{l}\text { Patients were unhappy with the way they } \\
\text { now looked and seriously undermined the } \\
\text { way they felt about themselves } \\
\text { Disease was a cause for worry, depression, } \\
\text { and low self-esteem } \\
\text { Difficult to participate in competitions in } \\
\text { school, leave school for doctor visits } \\
\text { Unmarried anticipate difficulty in getting } \\
\text { married, and the disease was not revealed to } \\
\text { the partner at the time of marriage due to } \\
\text { embarrassment or the fear of rejection. One } \\
\text { patient had been rejected by her in-laws and } \\
\text { told to get divorced if not cured } \\
\text { The severity of the psychosocial impact can } \\
\text { be seen in some patients who constantly } \\
\text { thought about their disease and could not } \\
\text { bear to look at themselves in the mirror } \\
\text { even if affected areas were covered }\end{array}$ \\
\hline Alghamdi et al ${ }^{25}$ & $\begin{array}{l}\text { Public perceptions and } \\
\text { attitudes toward vitiligo }\end{array}$ & 2012 & $n=924$ & Questionnaire & $\begin{array}{l}33.1 \% \text { believe vitiligo is contagious, } 56.1 \% \text { do } \\
\text { not want to marry a patient with vitiligo }\end{array}$ \\
\hline Wang et $\mathrm{a}^{26}$ & $\begin{array}{l}\text { Health-related quality of life } \\
\text { and marital quality of vitiligo } \\
\text { patients in China }\end{array}$ & 2011 & $n=101$ & $\begin{array}{l}\text { DLQI, SF-36, } \\
\text { ENRICH }\end{array}$ & $\begin{array}{l}>50 \% \text { of patients report relationship problems } \\
\text { with the opposite sex; most feel trouble and } \\
\text { shame when meeting a stranger or beginning a } \\
\text { sexual or emotional relation with a new partner } \\
16 \% \text { of patients with vitiligo reported sexual } \\
\text { problems, while } 25 \%-35 \% \text { had classical } \\
\text { symptoms of depression, such as loss of } \\
\text { sexual drive }\end{array}$ \\
\hline $\begin{array}{l}\text { Thompson } \\
\text { et } \mathrm{al}^{20}\end{array}$ & $\begin{array}{l}\text { Vitiligo linked to stigmatization } \\
\text { in British South Asian women: } \\
\text { a qualitative study of the } \\
\text { experiences of living with } \\
\text { vitiligo }\end{array}$ & 2010 & $\mathrm{n}=7$ & $\begin{array}{l}\text { Face-to-face or } \\
\text { e-mail interview }\end{array}$ & $\begin{array}{l}\text { Vitiligo is seen to negatively affect social } \\
\text { acceptability and marriage potential } \\
\text { Development of the "spoiled identity" } \\
\text { in relation to the internalization of the } \\
\text { experience of stigmatization }\end{array}$ \\
\hline Talsania et $\mathrm{al}^{6}$ & $\begin{array}{l}\text { Vitiligo is more than skin deep: } \\
\text { a survey of members of the } \\
\text { Vitiligo Society }\end{array}$ & 2010 & $n=520$ & Questionnaire & $\begin{array}{l}\text { Fear of getting sunburned on the affected } \\
\text { body areas can have major effects on } \\
\text { behavior and social participation } \\
\text { Patients are less willing to take part in } \\
\text { activities such as swimming and sports that } \\
\text { involve additional skin exposure }\end{array}$ \\
\hline Sampogna et $\mathrm{al}^{24}$ & $\begin{array}{l}\text { Impact of different skin } \\
\text { conditions on quality of life }\end{array}$ & 2013 & 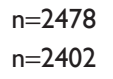 & $\begin{array}{l}\text { Skindex-29 (sx) } \\
\text { Skindex-17 (ps) }\end{array}$ & $\begin{array}{l}\text { Patients with vitiligo have low symptom } \\
\text { impairment but high psychosocial impairment }\end{array}$ \\
\hline Krishna et $\mathrm{a}^{38}$ & $\begin{array}{l}\text { Vitiligo impact scale: an } \\
\text { instrument to assess the } \\
\text { psychosocial burden of vitiligo }\end{array}$ & 2013 & $n=100$ & VIS & $\begin{array}{l}\text { Validation of VIS: scores on the scale as a } \\
\text { whole and responses to individual items } \\
\text { can serve as a guide for treatment decisions } \\
\text { including psychological intervention } \\
\text { May be useful to assess treatment modalities in } \\
\text { diminishing the psychosocial burden of vitiligo }\end{array}$ \\
\hline Chan et $\mathrm{a}^{39}$ & $\begin{array}{l}\text { Investigating factors associated } \\
\text { with depression of patients } \\
\text { with vitiligo in Singapore }\end{array}$ & 2011 & $\mathrm{n}=145$ & $\begin{array}{l}\text { Center for } \\
\text { Epidemiologic Studies } \\
\text { Depression Scale, } \\
\text { Rosenberg Self- } \\
\text { Esteem Scale, DLQI }\end{array}$ & $\begin{array}{l}\text { Patients with vitiligo affected in both quality } \\
\text { of life and self-esteem, which is particularly } \\
\text { negatively affected } \\
\text { Suicidal ideation is a major issue }\end{array}$ \\
\hline
\end{tabular}


Table I (Continued)

\begin{tabular}{|c|c|c|c|c|c|}
\hline Author & Title & Year & Size & Survey & Findings \\
\hline Alghamdi $^{37}$ & $\begin{array}{l}\text { Beliefs and perceptions of Arab } \\
\text { patients with vitiligo regarding } \\
\text { their condition }\end{array}$ & 2010 & $n=164$ & $\begin{array}{l}\text { Illness perception } \\
\text { questionnaire }\end{array}$ & $\begin{array}{l}>50 \% \text { of patients reported depression when } \\
\text { they think about their illness } \\
>50 \% \text { reported anxiety } \\
\text { In females, both anxiety and depression } \\
\text { were more prevalent in female patients }\end{array}$ \\
\hline
\end{tabular}

Acne

Marron et al ${ }^{18}$ oral isotretinoin

$\begin{array}{ll}\text { Tasoula et al }{ }^{16} & \text { The impact of acne vulgaris } \\ & \text { on quality of life and psychic } \\ & \text { health in young adolescents in } \\ & \text { Greece. Results of a population } \\ & \text { survey }\end{array}$

Shahzad et al ${ }^{9}$

Bez et al ${ }^{10}$

Roosta et al ${ }^{14}$

Kubota et al $^{19}$

Skin disease and stigma in emerging adulthood: impact on healthy development

Community-based

epidemiological study of psychosocial effects of acne in Japanese adolescents
Anxiety, depression, quality of life and patient satisfaction in patients with acne treated with

$2013 n=334$ DLQI, Health SF-36, Hospital Anxiety and Depression Scale

\section{$20|2 n=| 53 \mid \quad$ DLQI, CDLQI}

201

$n=950$

CADI impact of acne on university and related disability in patients with acne vulgaris
$2011 \quad n=140$

LSAS, HADS, Sheehan Disability Scale, interview by psychiatrist
201

2010 $\mathrm{n}=85$

Baseline DLQI I3.2 that is more negative than the general population

Mean \pm SD anxiety score was $8.9 \pm 3.9$, which is higher than the general population Depression was clinically significant in 12 cases out of 334

$21 \%$ of the acne adolescents were affected in their school work and personal activities due to acne

$19.4 \%$ were affected in their hobbies due to acne $19.2 \%$ of the students were affected in their personal and social lives, especially in their relationship building because of their acne on the face

$14 \%$ avoided swimming and other sports due to embarrassment; the same results were noticed in patients with back acne

Mean CADI score was 2.67 \pm 5.35

Acne had a greater psychosocial impact on females as compared to males Social phobia was diagnosed in $45.7 \%$ of patients with acne vulgaris and in $18.4 \%$ of control subjects: social phobia diagnosis predicted disability at work

Patients with acne vulgaris had higher avoidance scores in LSAS than controls Patients with acne vulgaris without social phobia had higher scores in HADS and LSAS than the patients with acne vulgaris with social phobia. They were more disabled in their occupational, social, and familial lives Social phobia seems to be a common psychiatric comorbidity, which may give rise to some additional disability among patients with acne vulgaris

Likelihood of experiencing perceived stigma was 3.19 times higher for those with acne compared to those without acne Students with acne were significantly more depressed than those without skin problems Girls were significantly more depressed than boys

Among students with acne, students who had acne with a duration of $>2$ years showed a significantly lower $\mathrm{MHI}$ score compared to those who reported having acne for $<6$ months; similar results for depression

$2014 \quad \mathrm{n}=48 \quad$ Acne Symptom and Impact Scale
The most frequently reported impacts were impacts on appearance, self-consciousness, annoyance, bothersomeness, mood, social criticism, embarrassment, confidence, and social withdrawal 
Table I (Continued)

\begin{tabular}{|c|c|c|c|c|c|}
\hline Author & Title & Year & Size & Survey & Findings \\
\hline Callender et $\mathrm{al}^{13}$ & $\begin{array}{l}\text { Racial differences in clinical } \\
\text { characteristics, perceptions } \\
\text { and behaviors, and } \\
\text { psychosocial impact of adult } \\
\text { female acne }\end{array}$ & 2014 & $n=208$ & $\begin{array}{l}\text { Patient Health } \\
\text { Questionnaire }\end{array}$ & $\begin{array}{l}\text { Depression rates were similar among White/ } \\
\text { Caucasian vs non-White/Caucasian patients } \\
\text { More White/Caucasian patients felt self- } \\
\text { conscious around other people } \\
\text { More non-White/Caucasian patients felt } \\
\text { that nonacne sufferers could not relate to } \\
\text { experiencing adult acne }\end{array}$ \\
\hline Darwish et al $^{17}$ & $\begin{array}{l}\text { Knowledge, beliefs, and } \\
\text { psychosocial effect of acne } \\
\text { vulgaris among Saudi patients } \\
\text { with acne }\end{array}$ & 2013 & $n=160$ & Questionnaire & $\begin{array}{l}13.3 \% \text {, affected schoolwork performance } \\
21.1 \% \text {, affected spousal relationship } \\
30.6 \% \text {, affected marriage willingness } \\
17.2 \% \text {, affected friendship relations }\end{array}$ \\
\hline Pruthi et al ${ }^{15}$ & $\begin{array}{l}\text { Physical and psychosocial } \\
\text { impact of acne in adult females }\end{array}$ & 2012 & $\mathrm{n}=\mathrm{II}$ & $\begin{array}{l}\text { Open-ended } \\
\text { questions }\end{array}$ & $\begin{array}{l}\text { Indian women believed that physical } \\
\text { attractiveness increased ability to secure jobs } \\
\text { and life partners } \\
\text { Ultimately felt that the nature and qualities } \\
\text { of a person mattered more in the long term }\end{array}$ \\
\hline Ritvo et al ${ }^{11}$ & $\begin{array}{l}\text { Psychosocial judgements and } \\
\text { perceptions of adolescents } \\
\text { with acne vulgaris: a blinded, } \\
\text { controlled comparison of adult } \\
\text { and peer evaluations }\end{array}$ & 2011 & $n=1,002$ & Questionnaire & $\begin{array}{l}\text { Social bullying was perceived to be greater in } \\
\text { patients with acne } \\
\text { Acne was associated with more negative } \\
\text { descriptors }\end{array}$ \\
\hline \multicolumn{6}{|l|}{ Psoriasis } \\
\hline $\begin{array}{l}\text { Martinez-Garcia } \\
\text { et } \mathrm{al}^{28}\end{array}$ & $\begin{array}{l}\text { Quality of life in persons living } \\
\text { with patients with psoriasis }\end{array}$ & 2014 & $n=130$ & DLQI, FDLQI, HADS & $\begin{array}{l}87.8 \% \text { of the cohabitants with patients with } \\
\text { psoriasis had impaired quality of life } \\
\text { FDLQI scores of cohabitants were significantly } \\
\text { associated with the DLQI scores of the patients } \\
\text { Anxiety and depression levels did not differ } \\
\text { between patients and cohabitants but were } \\
\text { significantly higher than in the control groups }\end{array}$ \\
\hline Cather $^{32}$ & $\begin{array}{l}\text { Psoriasis in children and } \\
\text { women: addressing some } \\
\text { special needs }\end{array}$ & 2014 & $n=60$ & Interview & $\begin{array}{l}\text { In women }<35 \text { years of age, the likelihood } \\
\text { of pregnancy was } 22 \% \text { lower than the } \\
\text { average, nondiseased population } \\
\text { Women with psoriasis also tended to have } \\
\text { fewer children than controls } \\
100 \% \text { of patients reported an adverse impact } \\
\text { on their intimate relationships, with } 91 \% \\
\text { related to sexual desire and } 79 \% \text { sexual ability }\end{array}$ \\
\hline Bewley et $\mathrm{al}^{30}$ & $\begin{array}{l}\text { Identifying individual } \\
\text { psychosocial and adherence } \\
\text { support needs in patients } \\
\text { with psoriasis: a multinational } \\
\text { two-stage qualitative and } \\
\text { quantitative study }\end{array}$ & 2014 & $\mathrm{n}=\mathrm{I}, 884$ & Survey & $\begin{array}{l}\text { Depressive symptoms associated with psoriasis } \\
\text { have in turn been associated with health-impairing } \\
\text { behavior patterns such as smoking, drinking, } \\
\text { and decreased physical activity or obesity } \\
\text { Questions relating to isolation, social stigma, } \\
\text { impact of psoriasis on activities, and feelings } \\
\text { of hopelessness should be included in } \\
\text { consultations }\end{array}$ \\
\hline Sampogna et $\mathrm{al}^{24}$ & $\begin{array}{l}\text { Impact of different skin } \\
\text { conditions on quality of life }\end{array}$ & 2013 & $\begin{array}{l}n=2,478 \\
n=2,402\end{array}$ & $\begin{array}{l}\text { Skindex-29 (sx) } \\
\text { Skindex-17 (ps) }\end{array}$ & $\begin{array}{l}\text { Patients with psoriasis had high symptom } \\
\text { impairment and high psychosocial impairment }\end{array}$ \\
\hline $\begin{array}{l}\text { Chularojanamontri } \\
\text { et } \mathrm{al}^{36}\end{array}$ & $\begin{array}{l}\text { The Simplified Psoriasis Index } \\
(\mathrm{SPI}) \text { : a practical tool for } \\
\text { assessing psoriasis }\end{array}$ & 2013 & $n=150$ & DLQI, SPI & $\begin{array}{l}\text { The close correlation between SPI-p } \\
\text { (psychosocial domain) and DLQI in } \\
\text { our study confirms that SPI-p is a good } \\
\text { instrument for assessing the psychological } \\
\text { impact of psoriasis }\end{array}$ \\
\hline Anstey et $\mathrm{al}^{29}$ & $\begin{array}{l}\text { Extending psychosocial } \\
\text { assessment of patients with } \\
\text { psoriasis in the UK, using a } \\
\text { self-rated, web-based survey }\end{array}$ & 2012 & $\mathrm{n}=1,760$ & Web-based survey & $\begin{array}{l}\text { Important social issues highlighted were a lack } \\
\text { of understanding of psoriasis by the public, } \\
\text { avoidance, or limitation of social activities } \\
\text { Negatively affects ability to interact socially } \\
\text { and make new friends and cancel social } \\
\text { engagements }\end{array}$ \\
\hline
\end{tabular}


Table I (Continued)

\begin{tabular}{|c|c|c|c|c|c|}
\hline Author & Title & Year & Size & Survey & Findings \\
\hline Sampogna et al ${ }^{35}$ & $\begin{array}{l}\text { Living with psoriasis: prevalence of } \\
\text { shame, anger, worry, and problems } \\
\text { in daily activities and social life }\end{array}$ & 2012 & $n=936$ & Skindex-29 & $\begin{array}{l}\text { Stigma affecting social domains such as } \\
\text { relationships, social activities, and work } \\
\text { Problems in work was also more frequent in } \\
\text { patients with palmoplantar psoriasis } \\
\text { Psoriasis may have a negative impact on work, } \\
\text { both for psychological and clinical reasons }\end{array}$ \\
\hline Armstrong et $\mathrm{al}^{31}$ & $\begin{array}{l}\text { Quality of life and work } \\
\text { productivity impairment among } \\
\text { patients with psoriasis: findings } \\
\text { from the National Psoriasis } \\
\text { Foundation survey data } \\
2003-20 \text { II }\end{array}$ & 2012 & $n=5,604$ & Survey & $\begin{array}{l}12 \% \text { of patients were unemployed } \\
92 \% \text { of those unemployed cited psoriasis as } \\
\text { the sole cause for unemployment } \\
\text { Patients with severe psoriasis had } 1.8 \text { times } \\
\text { greater chance of being unemployed } \\
49 \% \text { of patients who worked missed days } \\
\text { from work regularly due to psoriasis }\end{array}$ \\
\hline
\end{tabular}

Abbreviations: DLQI, Dermatology Life Quality Index; SF-36, Short Form-36; VIS, Vitiligo Impact Scale; SD, standard deviation; CADI, Cardiff Acne Disability Index; LSAS, Liebowitz Social Anxiety Scale; HADS, Hospital Anxiety and Depression Scale; MHI, Mental Health Inventory; ASIS, Acne Symptom and Impact Scale; FDLQI, Family Dermatology Life Quality Index; SPI, Simplified Psoriasis Index; CDLQI, Children's Dermatology Life Quality Index; ENRICH, evaluating and nurturing relationship issues, communication, happiness.

through severe cases of acne excoriée, in which patients are more likely to suffer from psychiatric conditions such as eating disorders. Furthermore, the severity of acne does not always correlate with the severity of emotional impact; even mild cases of acne have been reported to have significant emotional impact on the patients. This highlights the importance of the dermatologist to modify and adjust medical therapy to meet the patient's individual needs on QOL. Psychotherapy may complement treatment for acne well. ${ }^{33}$ Thus, the recognition of the psychosocial impact of acne will create a platform for health care providers to guide treatment goals and connect to patients, especially those who are suffering in silence.

\section{Vitiligo and marriage}

The psychosocial effects of vitiligo were primarily discussed to affect marriage potential and encounters with a new partner. Because the disease often has an onset in late adulthood, there is less of a focus on social activities and more of an emphasis on long-term, serious relationships. This is especially important as the priorities of an older population shift toward stability and commitment. Unlike the often temporary and mild nature of most acne, vitiligo has more permanent effects and higher symptom visibility. Vitiligo is also more poorly understood by the general public than acne, with some cultures still considering vitiligo contagious or a sexually transmitted disease. Because of the severe social stigma associated with vitiligo, there may be a higher sense of concern for permanency of the disease. Due to the long-term nature of the disease, patients' concerns focus on serious, lifelong potential relationships.

Psychosocial impact on vitiligo is also highly dependent on the individual's culture. A majority of patients affected by vitiligo are considered minorities with darker skin tones.
These can be seen in the patient population studied: Pahwa et al studied an Indian population, while Alghamdi et al studied an Arab patient population, Wang et al studied a Chinese population, and Chan et al studied a Singaporean population. Minorities often have different cultural values and traditions from the Western societies and many place high importance and special value in marriage. It has been reported that the USA and other Westernized countries with an individualistic mindset place an emphasis on love in marriage. ${ }^{34}$ However, eastern countries, such as India and Thailand, that have a collectivist economy view marriage as an opportunity to expand their collective workforce. ${ }^{34}$ In contrast, it has been suggested that in Westernized countries, the potential spouses are thought to be endowed only to each other and will not affect their extended families. ${ }^{34}$ This thought process is opposite to that of eastern countries, whose marital status affects their entire family. ${ }^{34}$ Thus, the prevalence of a visually prominent disease such as vitiligo can not only diminish the marriage potential of patients but also affect their families as a whole. Thus, one may also consider culture to play a strong role in the prevalence of discussion of marriage with patients with vitiligo.

Table 2 Erickson stages of development outline the psychosocial conflict and primary relationships formed in each age group

\begin{tabular}{lll}
\hline Age group & Psychosocial conflict & $\begin{array}{l}\text { Primary } \\
\text { relationships formed }\end{array}$ \\
\hline $\begin{array}{l}\text { Adolescent } \\
\text { (12-18 years old) }\end{array}$ & Identity vs confusion & Peers \\
Young adulthood & Intimacy vs isolation & Friends and lovers \\
(20-25 years old) & & \\
Middle adulthood & Generativity vs stagnation & Family and society \\
(26-64 years old) & & \\
\hline
\end{tabular}




\section{Psoriasis and work, family, and social relationships}

Lastly, psoriasis has a bimodal distribution of age of onset in early 20 s or mid 50 s, as well as high symptom visibility and impairment. This is reflected in the multidimensional impact of the disease encompassing work difficulties, social limitations, and family dysfunction. Psoriasis, unlike acne and vitiligo, can present on the palms and soles and interfere with their daily function. Patients suffer work impairment due to the pain from using their hands and feet. This functional debilitating effect of psoriasis is not seen in acne and vitiligo. Additionally, childbearing women are reportedly affected in reproductive capabilities, thus affecting their family lives.

Because psoriasis can interfere with work productivity, family life may suffer from an economic standpoint. Income serves as a foundation for a family to function. Thus, limitations on the inflow of income may cause stress and disruption among the family. Similarly, the high visibility of psoriasis as well as the pain experienced by the patients is a great discouragement to participation in social activities. With both work and social lives negatively affected, patients with psoriasis often suffer great intrapsychic distress, often developing anxiety and depression.

\section{Conclusion}

The psychosocial effects of skin disease vary from intrapsychic effects to marital and familial issues. One may also consider the prevalence of a disease in a particular ethnic group, as well as their cultural values, when evaluating the psychosocial effects as a whole. Overall, acne, vitiligo, and psoriasis have a strong impact on the patients' psyche as well as their relationships with others, correlating with the Erickson Stages of Development. Multiple dimensions of patients' life, such as work, relationships, social outings, and family, are affected by their skin. By recognizing these potential psychosocial impairments experienced by patients, dermatologists can guide their therapy to achieve positive physical, mental, and emotional health among their patients.

\section{Disclosure}

Dr John YM Koo is a speaker and/or consultant for Abbvie, Celgene, Jassen, Leo, Novartis and Promius Pharma. The authors report no other conflicts of interest in this work.

\section{References}

1. Merriam-Webster. Psychosocial. 2015. Available from: http://www. merriam-webster.com/dictionary/psychosocial. Accessed December 10, 2015 .
2. White GM. Recent findings in the epidemiologic evidence, classification, and subtypes of acne vulgaris. J Am Acad Dermatol. 1998;39(2 Pt 3):S34-S37.

3. Smithard A, Glazebrook C, Williams HC. Acne prevalence, knowledge about acne and psychological morbidity in mid-adolescence: a community-based study. Br J Dermatol. 2001;145(2):274-279.

4. Law MP, Chuh AA, Lee A, Molinari N. Acne prevalence and beyond: acne disability and its predictive factors among Chinese late adolescents in Hong Kong. Clin Exp Dermatol. 2010;35(1):16-21.

5. Yahya H. Acne vulgaris in Nigerian adolescents-prevalence, severity, beliefs, perceptions, and practices. Int $J$ Dermatol. 2009;48(5):498-505.

6. Talsania N, Lamb B, Bewley A. Vitiligo is more than skin deep: a survey of members of the Vitiligo Society. Clin Exp Dermatol. 2010;35(7):736-739.

7. Hautmann G, Panconesi E. Vitiligo: a psychologically influenced and influencing disease. Clin Dermatol. 1997;15(6):879-890.

8. Queiro R, Tejon P, Alonso S, Coto P. Age at disease onset: a key factor for understanding psoriatic disease. Rheumatology. 2014;53(7): 1178-1185.

9. Shahzad N, Nasir J, Ikram U, Asmaa-ul H, Qadir A, Sohail MA. Frequency and psychosocial impact of acne on university and college students. J Coll Physicians Surg Park. 2011;21(7):442-443.

10. Bez Y, Yesilova Y, Kaya MC, Sir A. High social phobia frequency and related disability in patients with acne vulgaris. Eur J Dermatol. 2011;21(5):756-760.

11. Ritvo E, Del Rosso JQ, Stillman MA, La Riche C. Psychosocial judgements and perceptions of adolescents with acne vulgaris: a blinded, controlled comparison of adult and peer evaluations. Biopsychosoc Med. 2011;5(1):11.

12. Alexis A, Daniels SR, Johnson N, Pompilus F, Burgess SM, Harper JC. Development of a new patient-reported outcome measure for facial acne: the Acne Symptom and Impact Scale (ASIS). J Drugs Dermatol. 2014;13(3):333-340.

13. Callender VD, Alexis AF, Daniels SR, et al. Racial differences in clinical characteristics, perceptions and behaviors, and psychosocial impact of adult female acne. J Am Acad Dermatol. 2014;7(7):19-31.

14. Roosta N, Black DS, Peng D, Riley LW. Skin disease and stigma in emerging adulthood: impact on healthy development. J Cutan Med Surg. 2010;14(6):285-290.

15. Pruthi GK, Babu N. Physical and psychosocial impact of acne in adult females. Indian J Dermatol. 2012;57(1):26-29.

16. Tasoula E, Gregoriou S, Chalikias J, et al. The impact of acne vulgaris on quality of life and psychic health in young adolescents in Greece. Results of a population survey. An Bras Dermatol. 2012;87(6):862-869.

17. Darwish MA, Al-Rubaya AA. Knowledge, beliefs, and psychosocial effect of acne vulgaris among Saudi acne patients. ISRN Dermatol. 2013;2013:929340.

18. Marron SE, Tomas-Aragones L, Boira S. Anxiety, depression, quality of life and patient satisfaction in acne patients treated with oral isotretinoin. Acta Derm Venereol. 2013;93(6):701-706.

19. Kubota Y, Shirahige Y, Nakai K, Katsuura J, Moriue T, Yoneda K. Community-based epidemiological study of psychosocial effects of acne in Japanese adolescents. J Dermatol. 2010;37(7):617-622.

20. Thompson AR, Clarke SA, Newell RJ, Gawkrodger DJ; Appearance Research Collaboration. Vitiligo linked to stigmatization in British South Asian women: a qualitative study of the experiences of living with vitiligo. Br J Dermatol. 2010;163(3):481-486.

21. Pahwa P, Mehta M, Khaitan BK, Sharma VK, Ramam M. The psychosocial impact of vitiligo in Indian patients. Indian J Dermatol Venereol Leprol. 2013;79(5):679-685.

22. Chan MF, Thng TG, Aw CW, Goh BK, Lee SM, Chua TL. Investigating factors associated with quality of life of vitiligo patients in Singapore. Int J Nurs Pract. 2013;19 Suppl 3:3-10.

23. Kent G, al-Abadie M. Factors affecting responses on Dermatology Life Quality Index items among vitiligo sufferers. Clin Exp Dermatol. 1996;21(5):330-333. 
24. Sampogna F, Tabolli S, Abeni D. Impact of different skin conditions on quality of life. G Ital Dermatol Venereol. 2013;148(3):255-261.

25. Alghamdi KM, Moussa NA, Mandil A, et al. Public perceptions and attitudes toward vitiligo. J Cutan Med Surg. 2012;16(5):334-340.

26. Wang KY, Wang KH, Zhang ZP. Health-related quality of life and marital quality of vitiligo patients in China. $J$ Eur Acad Dermatol Venereol. 2011;25(4):429-435.

27. Sangma LN, Nath J, Bhagabati D. Quality of life and psychological morbidity in vitiligo patients: a study in a teaching hospital from northEast India. Indian J Dermatol. 2015;60(2):142-146.

28. Martínez-García E, Arias-Santiago S, Valenzuela-Salas I, GarridoColmenero C, García-Mellado V, Buendía-Eisman A. Quality of life in persons living with psoriasis patients. $J$ Am Acad Dermatol. 2014;71(2):302-307.

29. Anstey A, McAteer H, Kamath N, Percival F. Extending psychosocial assessment of patients with psoriasis in the UK, using a self-rated, web-based survey. Clin Exp Dermatol. 2012;37(7):735-740.

30. Bewley A, Burrage DM, Ersser SJ, Hansen M, Ward C. Identifying individual psychosocial and adherence support needs in patients with psoriasis: a multinational two-stage qualitative and quantitative study. J Eur Acad Dermatol Venereol. 2014;28(6):763-770.

31. Armstrong AW, Schupp C, Wu J, Bebo B. Quality of life and work productivity impairment among psoriasis patients: findings from the National Psoriasis Foundation survey data 2003-2011. PLoS One. 2012;7(12):e52935.
32. Cather JC. Psoriasis in children and women: addressing some special needs. Semin Cutan Med Surg. 2014;33(2 Suppl 2): S42-S44.

33. Niemeier V, Kupfer J, Gieler U. Acne vulgaris-psychosomatic aspects. J German Soc Dermatol. 2006;4(12):1027-1036.

34. Levine R, Sato S, Hashimoto T, Verma J. Love and marriage in eleven cultures. J Cross-Cultural Psychol. 1995;26(5):554-571.

35. Sampogna F, Tabolli S, Abeni D, IDIMPRoVE investigators. Living with psoriasis: prevalence of shame, anger, worry, and problems in daily activities and social life. Acta dermato-venereologica. 2012;92(3):299-303.

36. Chularojanamontri L, Griffiths CE, Chalmers RJ. The Simplified Psoriasis Index (SPI): a practical tool for assessing psoriasis. J Invest Dermatol. 2013;133(8):1956-1962.

37. Alghamdi KM. Beliefs and perceptions of Arab vitiligo patients regarding their condition. Int J Dermatol. 2010;49(10):1141-1145.

38. Krishna GS, Ramam M, Mehta M, Sreenivas V, Sharma VK, Khandpur S. Vitiligo impact scale: an instrument to assess the psychosocial burden of vitiligo. Indian J Dermatol Venereol Leprol. 2013;79(2):205-210.

39. Chan MF, Chua TL, Goh BK, Aw CW, Thng TG, Lee SM. Investigating factors associated with depression of vitiligo patients in Singapore. J Clin Nurs. 2012;21(11-12):1614-1621.
Clinical, Cosmetic and Investigational Dermatology

\section{Publish your work in this journal}

Clinical, Cosmetic and Investigational Dermatology is an international, peer-reviewed, open access, online journal that focuses on the latest clinical and experimental research in all aspects of skin disease and cosmetic interventions. All areas of dermatology will be covered; contributions will be welcomed from all clinicians and

\section{Dovepress}

basic science researchers globally. This journal is indexed on CAS The manuscript management system is completely online and includes a very quick and fair peer-review system, which is all easy to use. Visit http://www.dovepress.com/testimonials.php to read real quotes from published authors. 